\title{
Jacques Réattu sous le signe de la Révolution
}

\section{Michel Biard}

\section{(2) OpenEdition}

\section{Journals}

Édition électronique

URL : https://journals.openedition.org/ahrf/1152

DOI : 10.4000/ahrf.1152

ISSN : 1952-403X

Éditeur :

Armand Colin, Société des études robespierristes

Édition imprimée

Date de publication : 1 septembre 2001

Pagination : 142-143

ISSN : 0003-4436

\section{Référence électronique}

Michel Biard, « Jacques Réattu sous le signe de la Révolution», Annales historiques de la Révolution

française [En ligne], 325 । juillet-septembre 2001, mis en ligne le 10 avril 2006, consulté le 23 avril 2022 URL : http://journals.openedition.org/ahrf/1152 ; DOI : https://doi.org/10.4000/ahrf.1152

Ce document a été généré automatiquement le 23 avril 2022.

Tous droits réservés 


\title{
Jacques Réattu sous le signe de la Révolution
}

\author{
Michel Biard
}

\section{RÉFÉRENCE}

Jacques Réattu sous le signe de la Révolution, catalogue de l'exposition réalisée par le Musée de la Révolution française (30 juin - 2 octobre 2000), Vizille, coédité par Actes Sud, $2000,128 \mathrm{p}$.

1 Pour beaucoup de nos concitoyens, le nom de Réattu est avant tout associé au musée éponyme d'Arles qui conserve l'essentiel de ses œuvres et rares sont sans doute ceux qui peuvent se vanter de connaître un tant soit peu cet artiste en dépit de la thèse que lui a consacrée en 1977 une historienne de l'Art, Katrin Simons. Ce travail a pourtant fait l'objet d'une belle publication, en 1985, par les éditions Arthéna, mais il semble qu'une exposition telle que celle du Musée de la Révolution française accompagnée d'un très beau catalogue vendu à un prix raisonnable (à l'échelle des prix pratiqués par les maisons d'édition qui se spécialisent dans les livres d'Art) devrait contribuer fortement à une meilleure connaissance de l'artiste.

2 Jacques Réattu, né à Arles en 1760, réalise ses premières pièces dans les années 1770 et c'est en 1790, alors que la Révolution le touche encore peu, qu'il obtient une première consécration, celle de sa réception pour le prix de Rome (sur ces rituels de l'École des Beaux-Arts, nous renvoyons le lecteur au bel ouvrage de Philippe Grunchec, Les concours des prix de Rome, 1797-1863, publié en 1986). Ses années sur les bords du Tibre, 1791 et 1792, sont marquées par la maturation de ses idées politiques et bien sûr par la fuite des pensionnaires de l'Académie royale devant les violences antirévolutionnaires des Romains, sans que l'on puisse déterminer chez Réattu (selon Katrin Simons) la part de l'adhésion sincère aux nouveaux principes et le souci d'obtenir des commandes là où les traditionnels mécènes disparaissent avec un régime devenu ancien. L'année 1794 est pour lui une année clé avec les projets pour son Triomphe de la Liberté et ses travaux 
dans l'église des Prêcheurs de Marseille transformée en temple de la Raison. Il réalise alors certains de ses plus beaux dessins, notamment son atemporel Travail repoussant la Misère. Aux lendemains de thermidor, il se tourne de toute évidence vers des sujets plus anodins et, par le biais d'un héritage paternel, il abandonne temporairement l'Art pour une autre culture, celle de la terre, ce qui lui permet au demeurant d'éviter de mettre son talent au service de Napoléon Bonaparte. Ce n'est, significativement, qu'avec la Restauration qu'il reprend ses pinceaux. Il meurt en 1833.

3 Outre des éléments biographiques bien plus détaillés que ces trop rapides notes, le lecteur trouvera divers textes qui accompagnent une riche iconographie. Sans vouloir tous les citer (mais ils méritent tous lecture), mentionnons une contribution de KatrinSimons qui livre une minutieuse analyse du Triomphe de la Liberté et met cette œuvre en parallèle avec la fameuse toile de Regnault, La Liberté ou la Mort. Un texte de Michel Delon apporte de précieux éclairages sur le mythe de Prométhée au xviIIesiècle. Enfin, Claude Badet évoque le décor du «temple de la Raison» de Marseille où le citoyen (et le lecteur!) est convié à une, dans le cadre d'une politique culturelle voulue par un représentant en mission, en l'occurrence Maignet (dont les idées et pratiques ont été déjà, à plusieurs reprises, analysées par Jacques Guilhaumou).

Pour tous ceux qui n'auraient pas eu la chance de voir cette exposition dans l'Isère, il convient de s'adonner au plus vite au plaisir d'une découverte, celle de ce très beau catalogue. Le plaisir sera double si, passant d'Arles à Lille, mais aussi de Rome à Florence, le lecteur se plonge avec délice dans Esther et le diplomate, roman de Frédéric Vitoux (éditions du Seuil, 1998) qui fait revivre le peintre Jean-Baptiste Wicar et ses compagnons réfugiés à Florence en 1793 après avoir été chassés... de Rome. 